\title{
Modeling the effects of palm-house proximity on the theoretical risk of Chagas disease transmission in a rural locality of the Orinoco basin, Colombia
}

\author{
Diana Erazo and Juan Cordovez
}

\begin{abstract}
Background: Chagas disease is a major public health concern in Latin America and it is transmitted by insects of the subfamily Triatominae, including Rhodnius spp. Since palm trees are ubiquitous in Colombia and a habitat for Rhodnius spp., the presence of palms near villages could increase contact rates between vectors and humans. Therefore, knowing whether a relationship exists between the proximity of palms to villages and the abundance and distribution of vectors therein, may be critical for Chagas disease prevention programs. Adapting a mathematical model for R. prolixus population dynamics in a small village, we model the implications of changing distances between palms and dwellings, to the risk of Chagas disease infection.

Methods: We implemented a mathematical model that reflects $R$. prolixus population dynamics in a small village located in the department of Casanare (Colombia) to study the role of palm-house proximity. We varied the distance between palms and houses by monitoring the network global efficiency metric. We constructed 1,000 hypothetical villages varying distances and each one was run 100 times.

Results: According to the model, as palm-house proximity increases, houses were more likely to be visited by triatomine bugs. The number of bugs per unit time increased progressively in a non-linear fashion with high variability. We stress the importance of village configuration on the model output.

Conclusions: From a theoretical perspective, palm-house proximity may have a positive effect on the incidence of Chagas disease. The model predicts a 1\% increase in new human cases per year when houses and palms are brought closer by $75 \%$.
\end{abstract}

Keywords: Mathematical modeling, Chagas disease, Rhodnius prolixus, Risk factors, House infestation, Palm proximity

\section{Background}

Chagas disease is a major vector-borne disease in Latin America, caused by the parasite Trypanosoma cruzi. The parasite is mainly transmitted to mammal hosts by the feces of triatominae blood-sucking insects [1]. Since palm trees are one of the most common habitats of sylvatic triatomines and these trees often are near villages, palms constitute a risk factor for human infection [2-7].

\footnotetext{
* Correspondence: jucordov@uniandes.edu.co BIOMAC, Universidad de los Andes, Carrera 1 E No. 19A 40, Bogotá 111711 Colombia
} International License (http://creativecommons.org/licenses/by/4.0/), which permits unrestricted use, distribution, and reproduction in any medium, provided you give appropriate credit to the original author(s) and the source, provide a link to the Creative Commons license, and indicate if changes were made. The Creative Commons Public Domain Dedication waiver (http://creativecommons.org/publicdomain/zero/1.0/) applies to the data made available in this article, unless otherwise stated. of large palm trees with complex crowns are often infested by triatomines [8]. While some triatomines are opportunistic palm inhabitants, one study suggested that most of the species in the tribe Rhodniini are palm-specialized [9]. In Colombia, natural infections with T. cruzi have been found in 15 triatomine species [10], with Rhodnius prolixus as the main vector since it has domiciliary anthropophilic habits and has a wide geographical distribution in the Orinoco region $[7,11,12]$. 
Previous work from our group in the municipality of Mani Casanare (Orinoco region) [12], found that Attalea butyracea, a large-crowned palm, is ubiquitous and has large $R$. prolixus densities $[7,13]$ with high natural rates of infection with $T$. cruzi [12]. Interestingly, the same study reported low colonization indices of households [12] and residents mentioned often seeing adult insects come by at night supposedly attracted by lights [14]. Taken together, the close vector-palm association and the proximity between houses and palms, despite low domiciliation, create a unique mixture of risk factors that may partially explain the endemicity of the region [7].

The quantitative relationship between multiple factors that impact insect migrations from palms trees (e.g., light and distance between sylvatic and domestic habitats) and the risk of human infections is minimally understood [14-16]. In this study, we focus solely on the relationship between the proximity of palms to village dwellings and the possible risk of Chagas disease infection among the village inhabitants.

\section{Methods}

As described in Additional file 1 and [14], we developed a mathematical model that studies $R$. prolixus population dynamics in a village, which includes movement between habitats or patches (i.e. houses and palm trees).

In this study, our model assumes that insect movement between patches is determined by two interacting mechanisms: (i) proximity between patches promotes insect migration; and (ii) light makes a house twice as attractive for an insect compared to the same house without a light. The assumed mathematical relation between distance, light presence and habitat attractiveness is presented in Additional file 1 . In this study we wanted to artificially alter the average distance between houses and palms while maintaining a constant light stimuli in the village (to test only for the effects of distance). To do so, we maintained the palms at their original occurrence site and changed the location of the houses.

To compute average distance between houses and palms, we use a modified version of the network metric, global efficiency (GE), from Latora \& Marchiouri [17]. The concept of network efficiency indicates how easily information travels between network nodes. In our study, network efficiency measures the ease for insects to move between two types of patches, i.e. dwellings and palms. GE is a measure of functional integration and computed as the inverse of the common Average Path Length (APL) [18]. Unlike APL, GE can be computed on a disconnected network because movements between detached patches are defined to have infinite APL, which corresponds to zero GE [19]. Since our focus was palm proximity, we computed the GE using only the connections that have palms as the origin patch and houses as the destination patch. We called this measure the palm-house efficiency (PHE).

We created 1,000 scenarios in which palm locations were fixed but house locations changed randomly while remaining within the village-limit. For each scenario, we computed the PHE and found that it naturally varied between 0.1 and 1 . In our study, we were not able to randomly generate PHE values below 0.1. Note that if we artificially arrange house locations corresponding to a zero PHE, the network between houses and palms is entirely disconnected. A PHE equal to 0.1 produced an average of 2.65 connections, with an average distance of $228 \mathrm{~m}$ between houses and palms (out of the 3030 possible connections). For a PHE equal to 1, we obtained 63.24 connections with an average distance of $194 \mathrm{~m}$.

During each scenario run, we computed two epidemiological indices: the proportion of visited houses at steady state $(\mathrm{PVH})$ and the average number of insects per visited house per unit of time (VI). In addition, we computed the number of clusters $(\mathrm{NC})$ and the proportion of patches in the biggest cluster (PPBC).

\section{Results and discussion}

All the runs started with the same initial conditions: palms at their carrying capacity and no individuals in houses. Initial conditions that assumed that not every palm is infested produced very similar results so we decided to go with the worst-case scenario. Figure 1 shows the village configuration network for low, intermediate and high PHE, panels a to c respectively, obtained after a single model simulation.

Our results showed that a higher PHE (i.e. a close proximity between palms and houses) resulted in an increase of the epidemiological indices (Fig. 2). When PHE is equal to 0.01, PVH and VI are low: less than 5\% of the houses are visited and have less than one visiting insect per house per day (if PHE is zero then PVH and $\mathrm{VI}$ are zero). Increasing PHE to $20 \%$ produces a $\mathrm{PVH}$ increase of about $60 \%$, while VI increases to 2 . This increase in PHE is accompanied by a notable decline in the NC from 39 to 16 clusters, and a $15 \%$ increase in $\mathrm{PPBC}$ that reflects habitat integration. From this point, as we continue to increase PHE, the mean and standard deviation of PVH and VI follow a linear trend, reaching a PVH equal to 0.9 and VI equal to 3.2.

Using VI and PVH, we estimated the effect of palm proximity on the risk of Chagas disease infection. To this end, we used $R$. prolixus natural infection in the region, the estimated triatomine bug feeding rate on humans, and the probability of transmission per contact with an infected triatomine (for further details see the appendix and reference [14]). We found that the number of per-capita cases per year has a saturation effect. When PHE is equal to $7 \%$, 


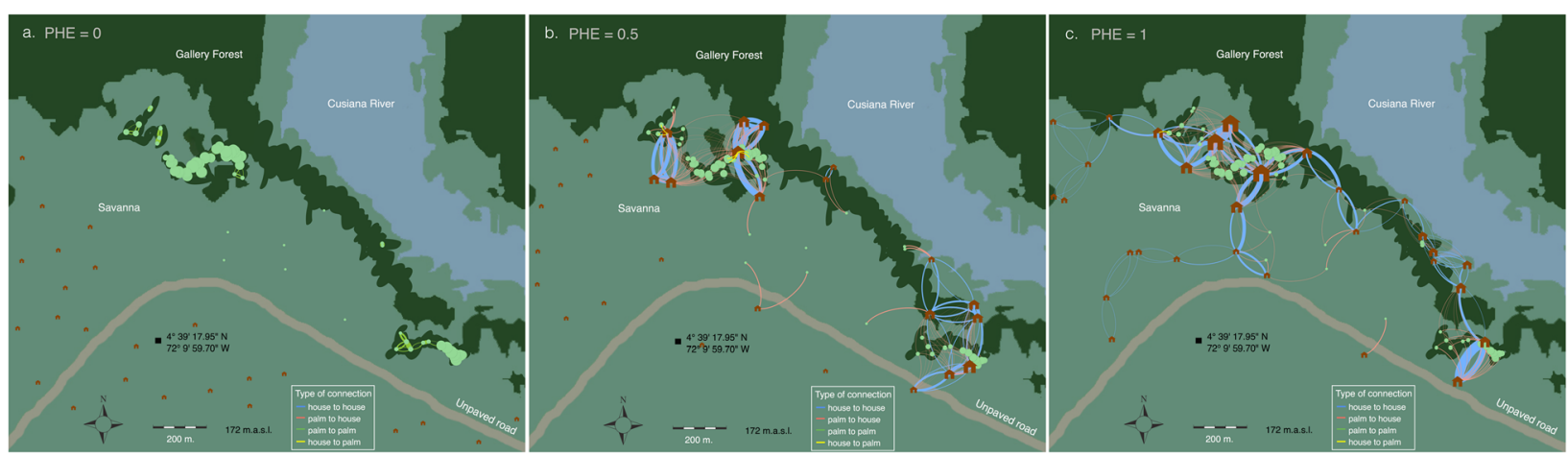

Fig. 1 Networks panels. For illustration purposes, we show a network example of the lowest (a), medium (b) and highest output (c) of Palm-House Efficiency (PHE) at steady state. Village landscape was maintained including palm locations. Locations of human dwellings were changed among scenarios to vary PHE. Circle and house icons symbolize palm trees and human dwellings, respectively, and the number of individuals visiting a habitat is represented by the icon's size. The color of the connections between habitats illustrates the direction of the link (house to house: blue; palm to house: red; house to palm: yellow; and palm to palm: green) and their width is related to the flow of insect moving from an origin to a destiny patch. When the PHE is equal to zero (a) there are no connections between houses and palms. As PHE increases (b) more connections appear because houses with lights at reachable distances increase in the village. Panel $\mathbf{c}$ shows a simulation in which a high proportion of human dwellings are visited due to an increase in the overall network connectivity

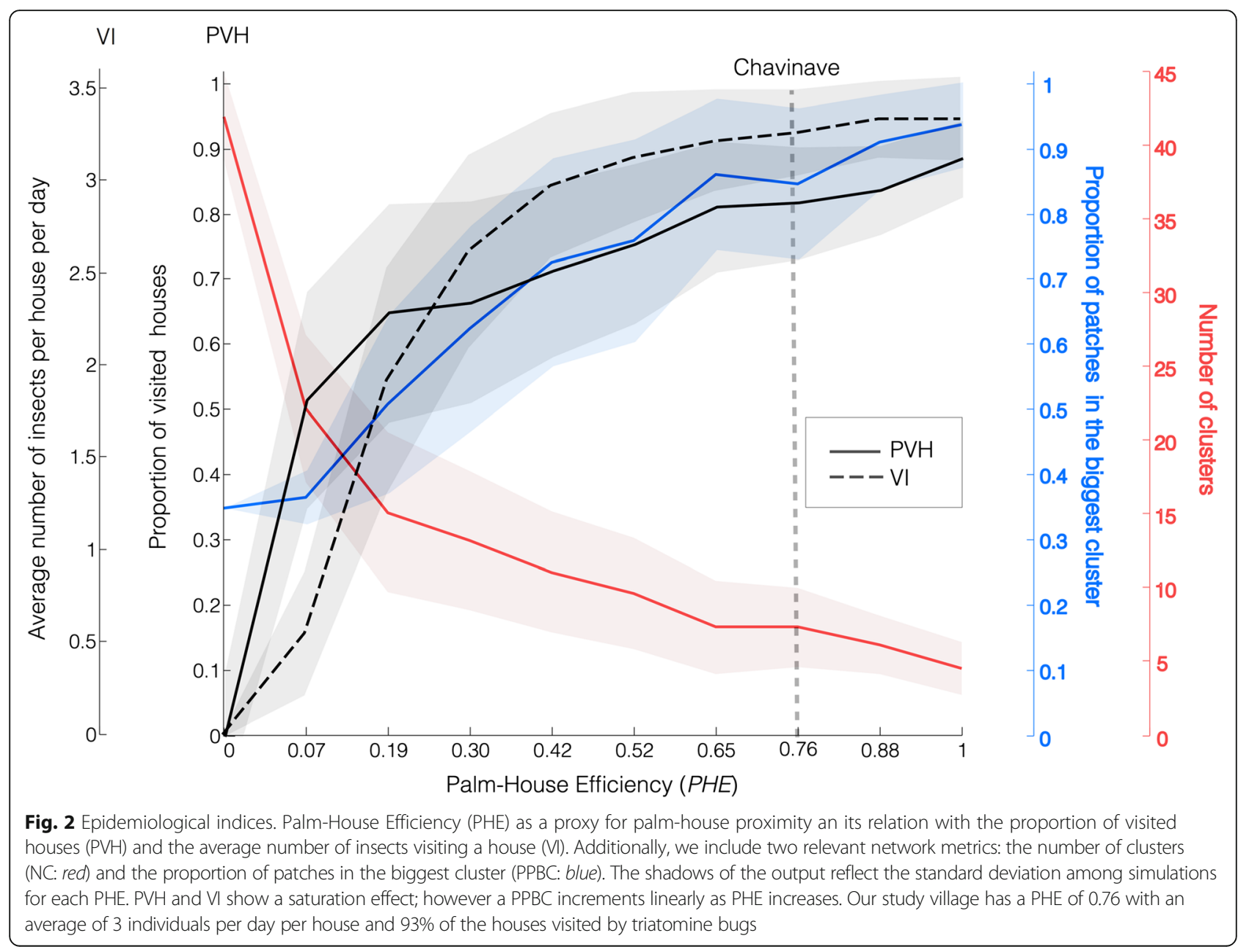


we computed an average of 1 case per 1,000 people per year, reaching an average maximum of 8.9 cases. However, higher variability is observed at intermediate values (Fig. 3) suggesting that the same PHE could result in different epidemiological situations. Chavinave has a PHE of $76 \%$ and a population of 122 people. Thus, using the model we estimate a new case every year. If we could hypothetically alter PHE to be $30 \%$, by relocating dwellings, then the number of cases could be reduced by $50 \%$.

A recent study suggested that at low PHE human risk infection due to vectorial transmission would be very low [20]. When PHE increases, high variability of epidemiological variables occurs among various studies and the need to examine particular house configurations within villages is critical [21-23]. In practice, the level of house-palm proximity can vary by at least three simple mechanisms: (i) keeping a single palm or a few palms near houses in the middle of the village [8]; (ii) introducing a single house or few houses into or near a gallery forest [21]; and (iii) adding a connected network of dwellings to a house that is connected to the forest. These scenarios result in high PPBC and low NC. These types of networks allow for the movement of sylvatic triatomines first from palms to a single house, and then to the rest of the village.
Under some simulations, we observed the formation, merely by chance, of a palm-only network detached from human dwellings. This network was capable of sustaining insect populations that were confined to the sylvatic cycle. This situation may be supported biologically if insects have other feeding sources, such as sylvatic vertebrates possibly associated with palms that could eliminate their need to feed on humans [6, 24].

\section{Conclusions}

In conclusion, our model predicts that palm-house proximity could play a significant role in human infection risk with T. cruzi, as suggested by Feliciangeli et al. [20]. Moreover, Saldaña et al. [25] reported dogs in a rural location in Panama, were 11.6 times more likely to become infected if Attalea butyracea palms were present in the peridomicile. The effectiveness of vector control strategies could increase by considering the flying ability of triatomine bugs [15] and recognizing the role that palm-house proximity plays in house infestation and re-infestation after control strategies [23, 26]. For instance, one could control vectors using efficient physical barriers, such as window screens, on targeted dwellings near palms [26-28]. As a control strategy, we may be able to reduce insect migration from palms by reconsidering the location of dwellings near palms and creating a buffer zone surrounding such dwellings.

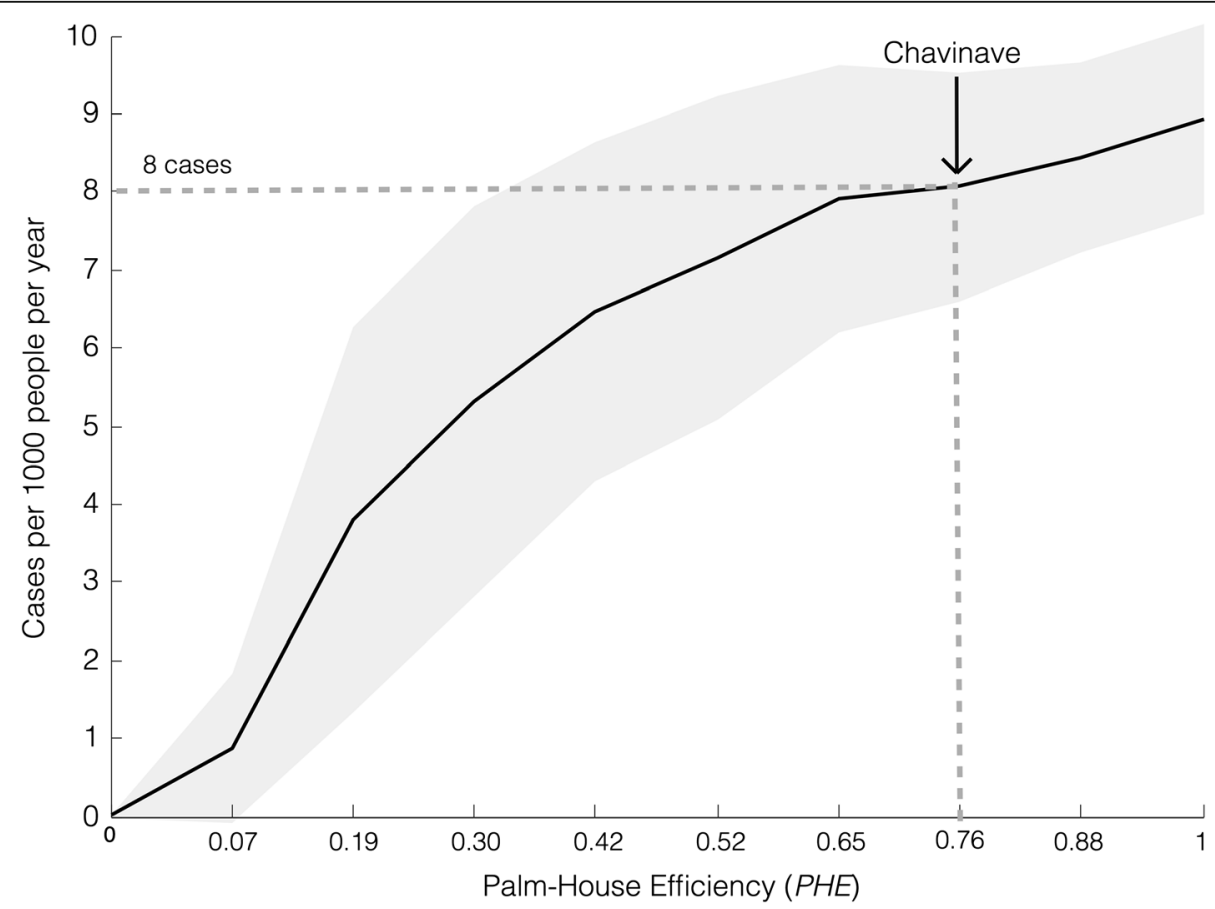

Fig. 3 Predicted number of cases as function of PHE. We computed the number of new cases per human per year based on the model output indices: VI and PVH. Additionally for this calculation, we considered reported values such as proportion of infected insects, insect biting rate, triatomine feeding rate on humans and probability of transmission per contact with an infected triatomine. For our study area, Chavinave village, the model predicted 8 cases per 1,000 people per year. For further details, see Additional file 1 


\section{Additional file}

Additional file 1: Mathematical model description, parameters and Trypanosoma cruzi infection prediction. (DOCX $102 \mathrm{~kb}$ )

\section{Abbreviations}

APL: Average path length; GE: Global efficiency; NC: Number of clusters; PHE: Palm-house efficiency; PPBC: Proportion of nodes in the biggest cluster; PVH: Proportion of visited houses; VI: Visiting index

\section{Acknowledgements}

The authors would like to acknowledge support from the office of the vice president for research at Universidad de los Andes. In addition we would like to thank the reviewers for their valuable comments.

\section{Funding}

This work was supported by the vice-president for research at Universidad de los Andes.

\section{Availability of data and materials}

The data supporting the conclusions of this article are included within the article. A detailed model formulation is described in Additional file 1.

\section{Authors' contributions}

DE and JC conceived the study and computational work, analyzed the results and wrote the manuscript. Both authors read and approved the final manuscript.

\section{Competing interests}

The authors declare that they have no competing interests.

\section{Consent for publication}

Not applicable.

\section{Ethics approval and consent to participate}

Not applicable.

\section{Received: 6 April 2016 Accepted: 11 November 2016}

Published online: 18 November 2016

\section{References}

1. Lent H, Wygodzinsky P. Revision of the Triatominae (Hemiptera, Reduviidae), and their significance as vectors of Chagas disease. Bull Am Museum Nat Hist. 1979;163:123-520

2. Gómez-Núñez JC. Resting places, dispersal and survival of CO60-tagged adult Rhodnius prolixus. J Med Entomol. 1969;6:83-6.

3. Castro MCM, Barrett TV, Santos WS, Abad-Franch F, Rafael JA. Attraction of Chagas disease vectors (Triatominae) to artificial light sources in the canopy of primary Amazon rainforest. Mem Inst Oswaldo Cruz. 2010;105:1061-4.

4. Ricardo-Silva AH, Lopes CM, Ramos LB, Marques WA, Mello CB, Duarte R, et al. Correlation between populations of Rhodnius and presence of palm trees as risk factors for the emergence of Chagas disease in Amazon region Brazil. Acta Trop. 2012;123:217-23.

5. Hurtado LA, Calzada JE, Pineda V, González K, Santamaría AM, Cáceres L, et al. Conocimientos y factores de riesgo relacionados con la enfermedad de Chagas en dos comunidades panameñas donde Rhodnius pallescens es el vector principal. Biomedica. 2014;34:260-70.

6. Lima MM, Coutinho CFS, Gomes TF, Oliveira TG, Duarte R, Borges-Pereira J, et al. Risk presented by Copernicia prunifera palm trees in the Rhodnius nasutus distribution in a chagas disease-endemic area of the Brazilian northeast. Am J Trop Med Hyg. 2008;79:750-4.

7. Angulo VM, Esteban L, Luna KP. Attalea butyracea próximas a las viviendas como posible fuente de infestación domiciliaria por Rhodnius prolixus (Hemiptera: Reduviidae) en los Llanos Orientales de Colombia. Biomedica. 2012:32:277-85.

8. Abad-Franch F, Lima MM, Sarquis O, Gurgel-Gonçalves R, Sánchez-Martín M, Calzada J, et al. On palms, bugs, and Chagas disease in the Americas. Acta Trop. 2015;151:126-41.

9. Abad-Franch F, Monteiro FA, Jaramillo ON, Gurgel-Gonçalves R, Dias FBS, Diotaiuti L. Ecology, evolution, and the long-term surveillance of vector- borne Chagas disease: A multi-scale appraisal of the tribe Rhodniini (Triatominae). Acta Trop. 2009:110:159-77.

10. Guhl F, Aguilera G, Pinto N, Vergara D. Actualización de la distribución geográfica y ecoepidemiología de la fauna de triatominos (Reduviidae: Triatominae) en Colombia. Biomedica. 2007;27:143-62.

11. Fitzpatrick S, Feliciangeli MD, Sanchez-Martin MJ, Monteiro FA, Miles MA Molecular genetics reveal that silvatic Rhodnius prolixus do colonise rural houses. PLoS Negl Trop Dis. 2008;2:e210.

12. Rendon LM, Guhl F, Cordovez JM, Erazo D. New scenarios of Trypanosoma cruzi transmission in the Orinoco region of Colombia. Mem Inst Oswaldo Cruz. 2015:110:283-8.

13. Urbano P, Poveda C, Molina J. Effect of the physiognomy of Attalea butyracea (Arecoideae) on population density and age distribution of Rhodnius prolixus (Triatominae). Parasit Vectors. 2015:8:1-12.

14. Erazo D, Cordovez J. The role of light in Chagas disease infection risk in Colombia. Parasit Vectors. 2016;9:9

15. Lazzari CR, Lorenzo MG. Exploiting triatomine behaviour: Alternative perspectives for their control. Mem Inst Oswaldo Cruz. 2009;104 Suppl 1:65-70.

16. Jácome-Pinilla D, Hincapie-Peñaloza E, Ortiz Ml, Ramírez JD, Guhl F, Molina J. Risks associated with dispersive nocturnal flights of sylvatic Triatominae to artificial lights in a model house in the northeastern plains of Colombia. Parasit Vectors. 2015:8:600

17. Latora V, Marchiori M. Efficient behavior of small-world networks. Phys Rev Lett. 2001:87:198701.

18. Rubinov M, Sporns O. Complex network measures of brain connectivity: Uses and interpretations. Neuroimage. 2010:52:1059-69.

19. Achard S, Bullmore E. Efficiency and cost of economical brain functional networks. PLoS Comput Biol. 2007;3:0174-83.

20. Feliciangeli MD, Sánchez-Martín MJ, Suárez B, Marrero R, Torrellas A, Bravo A, et al. Risk factors for Trypanosoma cruzi human infection in Barinas State, Venezuela. Am J Trop Med Hyg. 2007;76:915-21.

21. Ramirez-Sierra MJ, Herrera-Aguilar M, Gourbière S, Dumonteil E. Patterns of house infestation dynamics by non-domiciliated Triatoma dimidiata reveal a spatial gradient of infestation in rural villages and potential insect manipulation by Trypanosoma cruzi. Trop Med Int Health. 2010;15:77-86.

22. Barbu C, Dumonteil E, Gourbière S. Characterization of the dispersal of nondomiciliated Triatoma dimidiata through the selection of spatially explicit models. PLoS Negl Trop Dis. 2010;4:e777.

23. Leite GR, dos Santos CB, Falqueto A. Influence of the landscape on dispersal of sylvatic triatomines to anthropic habitats in the Atlantic Forest. J Biogeogr. 2011;38:651-63.

24. da Xavier SCC, Roque ALR, dos Lima VS, Monteiro KJL, Otaviano JCR, da Silva LFCF, Jansen AM. Lower richness of small wild mammal species and chagas disease risk. PLoS Negl Trop Dis. 2012;6:e1647.

25. Saldaña A, Calzada JE, Pineda V, Perea M, Rigg C, Gonzalez K, et al. Risk factors associated with Trypanosoma cruzi exposure in domestic dogs from a rural community in Panama. Mem Inst Oswaldo Cruz. 2015;110:936-44.

26. Barbu C, Dumonteil E, Gourbière S. Evaluation of spatially targeted strategies to control non-domiciliated Triatoma dimidiata vector of Chagas disease. PLoS Negl Trop Dis. 2011;5:e1045.

27. Barbu C, Dumonteil E, Gourbiere S. Optimization of control strategies for non-domiciliated Triatoma dimidiata, Chagas disease vector in the Yucatan Peninsula, Mexico. PLoS Negl Trop Dis. 2009;3:e416.

28. Rosecrans K, Cruz-Martin G, King A, Dumonteil E. Opportunities for improved Chagas disease vector control based on knowledge, attitudes and practices of communities in the Yucatan Peninsula, Mexico. PLoS Negl Trop Dis. 2014:8:e2763. 